\title{
Interpersonal Rejection Anxiety Questionnaire (IRAQ): Psychometric Properties of the Greek Version
}

\author{
Theodoros A. Kyriazos ${ }^{1}$, Artemis Giotsa ${ }^{2}$ \\ ${ }^{1}$ Department of Psychology, Panteion University, Athens, Greece \\ ${ }^{2}$ Faculty of Education, University of Ioannina, Ioannina, Greece \\ Email: th.kyriazos@gmail.com, agiotsa@uoi.gr
}

How to cite this paper: Kyriazos, T. A., \& Giotsa, A. (2019). Interpersonal Rejection Anxiety Questionnaire (IRAQ): Psychometric Properties of the Greek Version. Psychology, 10, 1542-1563.

https://doi.org/10.4236/psych.2019.1011101

Received: July 25, 2019

Accepted: August 24, 2019

Published: August 27, 2019

Copyright () 2019 by author(s) and Scientific Research Publishing Inc. This work is licensed under the Creative Commons Attribution International License (CC BY 4.0).

http://creativecommons.org/licenses/by/4.0/

\section{(c) () Open Access}

\begin{abstract}
The purpose of this work was to evaluate the psychometric properties of the Interpersonal Relationship Anxiety Questionnaire (IRAQ) in Greek adults of the general population. The single factor structure of IRAQ was verified for the Greek context. We used CFA with covariates (MIMIC modeling) for the evaluation of invariance in multiple groups, regressing the latent variables and indicators onto three covariates: 1) age, 2) gender, 3) relationship status. The direct effects of the covariates on interpersonal anxiety were not statistically significant. That is the mean of interpersonal anxiety is not different at different levels of the covariates. Thus, population heterogeneity was absent in IRAQ. The direct effects of the three covariates on all indicators of interpersonal anxiety were not statistically significant. Thus, measurement invariance was supported. Additionally, reliability was adequate. Finally, correlation analysis revealed expected relations with fear of interpersonal relationships and parental rejection. IRAQ is a reliable and valid measure to use in the Greek context.
\end{abstract}

\section{Keywords}

Interpersonal Relationship Anxiety Questionnaire (IRAQ), Social Anxiety, Interpersonal Anxiety, CFA, MIMIC Model, Population Heterogeneity, Measurement Invariance, Greece

\section{Introduction}

The unusually prolonged vulnerability state of human infancy is liable for attachment patterns to caregivers (Bowlby, 1969, 1980, 1988). This need for significant others is sustained throughout the lifespan (Baumeister \& Leary, 1995). 
These early patterns for attachment progressively become attachment styles (e.g., attachment theory; Hazan \& Shaver, 1987; Simpson, 1999), and the challenge is shifted from preserving connection to the primary caregiver to establishing and maintaining intimacy in adult interpersonal relationships (Erikson, 1968; Reker et al., 1987; Steger, Beeby, Garrett, \& Kashdan, 2013).

\section{Interpersonal relationships and interpersonal/social anxiety}

Indeed, satisfying interpersonal relationships are related with numerous positive outcomes, including positive physical health self-esteem, and a sense of well-being and life satisfaction (Diener \& Seligman, 2002; Leary, 2004; Mruk, 2006; Sedikides, Oliver, \& Campbell, 1994). On the other hand, interpersonal anxiety (IA $)^{1}$ limits the ability to get involved in and continue interpersonal relationships and thus to gain the potential benefits of social support and intimacy from partners enhancing positive experiences and flourishing (Ferssizidis, Kashdan, Marquart, \& Steger, 2013; Safren \& Heimberg, 1999).

Interpersonal anxiety is defined as fear and avoidance of situations that may involve evaluation by others-especially significant others (Safren \& Heimberg, 1999; Safren, Hollander, Hart, \& Heimberg, 2001). It is described as a fear of being scrutinized by other individuals because this could potentially result in a negative evaluation and/or rejection (Rapee \& Heimberg, 1997; Rohner, 2014). Excessive interpersonal anxiety is related to interpersonal distress and with a significant diminishing of the overall life quality (Kessler et al., 1994; Safren, Heimberg, Brown, \& Holle, 1997).

Research evidence generally indicates that individuals with IA have dysfunctional interpersonal and cognitive styles that impair their social performance and increase the rejection possibility (Clark \& Wells, 1995; Kashdan \& Roberts, 2004a; Rapee \& Heimberg, 1997). Specifically, during social interactions, they tend to focus extensively on making a positive impression. However, often they perceive themselves incapable of achieving this goal because anxiety disrupts their social performance (Rapee \& Heimberg, 1997; Ferssizidis et al., 2013). Making every possible effort to reduce the probability of rejection, people with IA frequently attempt to control or escape anxious thoughts and emotional states by avoiding anxiety-provoking stimuli. Therefore, during social/interpersonal interactions they adopt a "protective" behaviors like limited eye contact or conversation with others to minimize the rejection possibility (Clark \& Wells, 1995). However, this rejection prevention "strategy", makes the socially anxious individual less available and responsive, thus less likely to pursue activities generating positive interpersonal outcomes (Ferssizidis et al., 2013; Kashdan, Ferssizidis, Farmer, Adams, \& McKnight, 2013). The impact of this unresponsiveness and/or unavailability can be even greater on certain age categories like adolescents (Beidel \& Turner, 1998).

By closely focusing extensively on signs of negative evaluation, high-IA individuals may neglect positive aspects during their social interactions, because this

${ }^{1}$ The term Interpersonal Anxiety is used interchangeably with the term Social Anxiety as emerged by the literature review. 
is more consistent with their negatively distorted self-views, worldviews (Rohner, 1975, 1986) or mental representations (Baldwin, 1992; Epstein, 1994; Rohner \& Khaleque, 2016). These distortions and biases impair their ability to respond to social interactions, a variable that is potentially fueling positive interpersonal outcomes such as intimacy (Davis, 1982; Kashdan \& Roberts, 2004b), or positive resonance (Fredrickson, 2013). Perceived interpersonal rejection (see also Rohner, 2014; Rohner, 2016) may contribute to more generalized biased cognitive estimations. For example, individuals recalling a time when they felt accepted by others gave higher estimates of room temperature than those in the same room who perceived they were rejected (Conway, Tugade, Catalino, \& Fredrickson, 2013; Zhong \& Leonardelli, 2008). Moreover, compared to their less anxious peers, high-IA individuals are more likely: 1) to rate their sexual episodes as less enjoyable and 2) to feel less emotionally connected to their sex partners (Ferssizidis et al., 2013). Generally, high-IA individuals react to potential interpersonal evaluative situations with more self-focused attention than low-IA individuals (see Hartman, 1983; Hope, Gansler, \& Heimberg, 1989; Rapee \& Heimberg, 1997).

Given this significant effect of IA on interpersonal behavior, it is considered a negatively valenced personality variable regarding relationship outcomes. Interpersonal anxiety is found to be negatively associated with Positive Affect (Brown, Chorpita, \& Barlow, 1998; Kashdan, 2007; Naragon-Gainey, Watson, Gamez, \& Simms, 2005; Watson, 2016; Watson, \& Markon, 2009) and with high Negative Affect levels and while it has a moderately negative relation with curiosity and exploration (Ferssizidis et al., 2013; Kashdan \& Collins, 2010; Kashdan, Weeks, \& Savostyanova, 2011).

\section{The origins of Interpersonal anxiety}

Focusing on the origins of interpersonal anxiety, Sullivan (1953a, 1953b) proposed it is crucial during the human development process. He postulated that individuals attempt to diminish or eliminate interpersonal anxiety by limiting rejection by significant others or attachment figures (e.g. adult attachment; Bartholomew \& Horowitz, 1991; Hazan \& Shaver, 1987, 1990, 1994; Simpson \& Rholes, 1999). During childhood the discovery that some behaviors reduce interpersonal anxiety, while others increase it is a key learning experience. Thus, children learn to modify their behavior to decrease the possibility of experiencing interpersonal anxiety (Sullivan, 1953b) by rejection from significant others.

In other words, "our interpersonal actions are designed to invite, pull, elicit, draw, entice, or evoke restricted classes of reactions from persons with whom we interact, especially from significant others" (Kiesler, 1983: p. 198 cited by Bernier \& Dozier, 2002). Interpersonal transactions that include accepting behaviors decrease or eliminate interpersonal anxiety. In contrast, transactions that incorporate rejecting behaviors may increase interpersonal anxiety (Kiesler, 1996). Eliminating interpersonal anxiety may hence become the cause of 
maintaining self-preserving patterns of interpersonal behavior (Bernier \& Dozier, 2002).

Besides, based on the generalization of the secure attachment theory also in adult relationships (Bartholomew \& Horowitz, 1991; Hazan \& Shaver, 1987; Simpson, 1999) numerous studies associated parental rejection with psychological adjustment of children with effects over the entire adult life (Rohner, 1975; Rohner \& Rohner, 1980; Rohner, 2004; Rohner \& Britner, 2002). For example, Giotsa and Touloumakos (2014) proposed that the quality of the parent-child relationship typically affects the quality of peer relationships. Other researchers (Festa \& Ginsburg, 2011; Hummel \& Gross, 2001; Morris, 2001; Rohner, 2014; Rohner \& Khaleque, 2002) also confirmed that parental rejection is associated with higher levels of interpersonal anxiety during adulthood, that it would be a plausible predictor of it (Brook \& Schmidt, 2008). Perceived rejection from significant others is generally related to negative personality dispositions for children, adolescents and adults as well (Khaleque \& Rohner, 2012; Pfeffer, Lipkins, Plutchik, \& Mizruchi, 1988). Note, that previous research on interpersonal anxiety suggested that women generally experience higher levels of interpersonal anxiety than men (Garber \& Flynn, 2001; La Greca \& Lopez, 1998; Giotsa, Kyriazos, \& Mitrogiorgou, 2018).

\section{The Interpersonal Relationship Anxiety Questionnaire}

A new interpersonal anxiety measure is the Interpersonal Relationship Anxiety Questionnaire (Rohner, 2012). It is a unidimensional self-report instrument with nine statements describing symptoms of interpersonal anxiety and it is the focus of this work.

Previous research suggested that IRAQ had adequate internal consistency reliability, with a reported Cronbach's alpha coefficient of .87 (Brown et al., 2014) in a US sample of women, .88 in a Chinese sample of adolescents (Li \& Rohner, 2014), .93 in two Pakistani samples of adolescents (Naz \& Kausar, 2015), .83 in a Croatian sample of school children, and .89 in a Croatian sample of adolescents (Vulic-Prtoric \& Glavak-Tkalic, 2016). Consequently, the instrument was also translated in Urdu (Naz \& Kausar, 2015), Chinese (Li \& Rohner, 2014) Croatian, and Greek translation (Giotsa, 2015) and use (Giotsa, Stalikas, Kyriazos, \& Zergiotis, 2018).

The unidimensional structure of IRAQ was validated in all the above studies. Specifically, the validation study in the US was carried out in a sample of 78 women (Brown et al. 2014), with a mean age of 20.17 years. IRAQ was used twice on this sample with an interval of 30 days and the test-retest reliability was adequate $(r=70, p<.01)$. The researcher used Principal Components Analysis with Varimax rotation and all nine items were taping a single factor explaining $50 \%$ of the variance. Factor loadings ranged from .56 to .87 (Brown et al., 2014; quoted by Naz \& Kausar, 2015). The Chinese version of IRAQ (Li \& Rohner, 2014) was validated in a sample of 215 adolescents with a mean age of 16 years (as reproduced by Naz \& Kausar, 2015). The Urdu version of IRAQ was validated both on a clinical and a non-clinical sample of 300 female adolescents 
(Naz \& Kausar, 2015). The IRAQ factor structure was estimated by EFA and a CFA separately on each sample $(N=150$ each). First, an EFA with a Varimax rotation was carried out and all nine items were taping a single factor explaining $65 \%$ of the variance, factor loading from .47 to .76 (Naz \& Kausar, 2015). CFA confirmed the EFA results, loadings from .45 to .92 (Naz \& Kausar, 2015). When the mean scores of adolescents with somatoform disorders and adolescents with minor medical problems on IRAQ were compared, the two groups were found to be significantly different suggesting discriminant validity (Naz \& Kausar, 2015). The convergent validity of the scale (IRAQ) was assessed using the Personality Assessment Questionnaire (PAQ; Rohner \& Khaleque, 2005b; Rohner, Saavedra, \& Granum, 1978b). Divergent validity was evaluated using the Warmth/ Affection, a sub-scale of the Parental Acceptance-Rejection Questionnaire (PARQ; Rohner \& Khaleque, 2005a; Rohner, Saavedra, \& Granum, 1978a), see Naz and Kausar (2015) for details. Summing up the IRAQ validation studies, it has been validated in collectivistic and individualistic cultural contexts (Hofstede, 2001; Triandis, 1995), and special populations like female adolescents with somatoform disorders (Naz \& Kausar, 2015).

The purpose of the current study (see also Figure 1) is: 1) to validate IRAQ structure in the Greek general population; 2) to examine if age, gender or relationship status affects the IRAQ latent factor of interpersonal anxiety; 3) to examine if age, gender or relationship status affects the measurement invariance of any single item (1-9) of IRAQ; 4) to examine internal consistency reliability and convergent validity of IRAQ.

\section{Method}

\section{Participants}

Inclusion criteria in the study were the following 1) gender, and 2) ongoing relationship status (in a relationship or not). The sample consisted of 148 adults with a mean age of 28.24 years $(S D=9.53)$. Seventy-four participants were males (50\%). Seventy-four participants (50\%) had a close interpersonal relationship. Among the 74 participants in a relationship 30\% were dating, 15\% were married and $5 \%$ were living together with their partner. The mean duration of the relationship was 73.92 months, $(\mathrm{SD}=91.08)$ or 6.16 years. Most participants $(70 \%)$ had a university degree, $18 \%$ finished high-school, $12 \%$ had a postgraduate degree and $1 \%$ finished junior high-school. About half of the participants (44\%) were employed in the public or private sector, $26 \%$ were studying, $24 \%$ were unemployed, and $6 \%$ endorsed other choices (like freelance, retired and trainee). One hundred and forty participants had a Greek-orthodox religion and 8 participants endorsed "no religion".

\section{Materials}

Interpersonal Relationship Anxiety Questionnaire (IRAQ)

Interpersonal anxiety was measured with the Interpersonal Relationship Anxiety Questionnaire (IRAQ) by Rohner (2012). It comprises nine items describing possible emotional states of interpersonal anxiety (e.g., feeling upset, nervous 


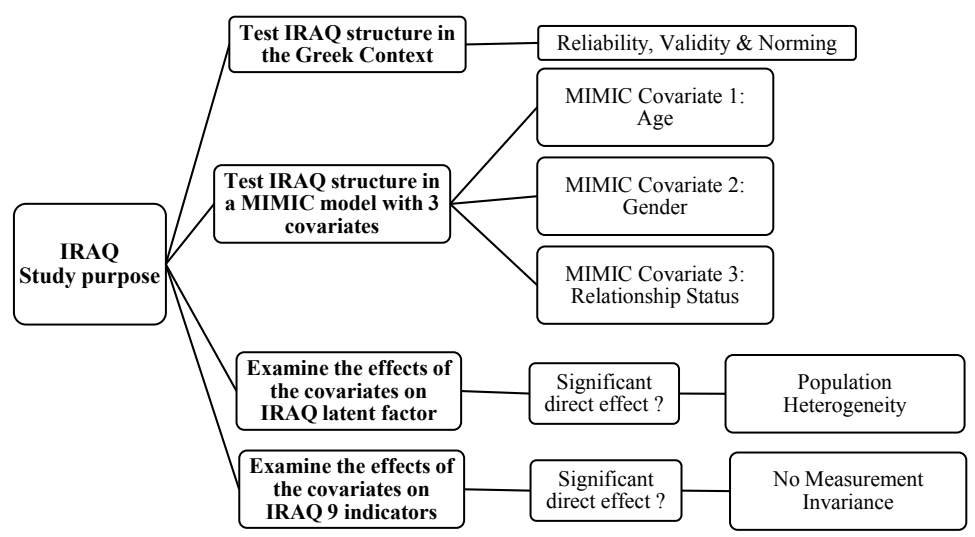

Figure 1. Purpose of the study.

or afraid). Participants evaluate each item on a 4-point scale with the levels: 4 (almost always true), 3 (sometimes true), 2 (rarely true) and 1 (almost never true). The higher the total score the more interpersonal anxiety the respondent perceives. The possible score ranges from 9 (lowest interpersonal anxiety) to 36 (highest interpersonal anxiety). Scores that range from 1 to 15 suggest normal anxiety, from 16 to 20 mild anxiety, from 21 to 27 moderate anxiety and from 28 to 36 severe anxiety (see also Naz \& Kausar, 2015).

Parental Acceptance-Rejection Questionnaire, Short form (PARQ).

In the Adult PARQ (Roher \& Khaleque, 2005a), adult participants reflect on their childhood experiences of maternal or paternal acceptance-rejection. There are two PARQ versions: mother and father versions. Statements in the two versions are identical except referencing "mother's" behavior in the mother version versus "father's" behavior in the father version. Individuals respond on a 4-point Likert-type scale from (4) "almost always true" to (1) "almost never true." The 24 items are tapping into four dimensions: Warmth/Affection, Hostility/Aggression, Indifference/Neglect and, finally, the Undifferentiated Rejection (Rohner \& Khaleque, 2005). Scores of the four acceptance-rejection dimensions are summed after reverse scoring the warmth/affection factor. The overall score is a measure of perceived acceptance-rejection ranging from 24 (maximum perceived acceptance) to 96 (maximum perceived rejection). Scores at or above 150 indicate the experience of significantly more caregiver rejection than acceptance. Scores between 140 and 149 indicate that respondents experience serious rejection but not necessarily more overall rejection than acceptance. On the other hand, scores between 60 and 120 suggest parental love.

Khaleque \& Rohner (2002) in a meta-analysis revealed the mean alpha coefficient, aggregated across all versions of the PARQ, at .89. Moreover, mean test-retest reliability (in a period from three weeks to seven years, Median $=15$ months) was .62 (Khaleque \& Rohner, 2002). Finally, factor analyses of the PARQ revealed a four-factor structure (Comunian \& Gielen, 2000; Gomez \& Rohner, 2011; Rohner \& Chaki-Sircar, 1988; Rohner \& Cournoyer, 1994; Rohner, Saavedra, \& Granum, 1978a). 
Fear of Intimacy Scale (FIS)

The Fear of Intimacy Scale (FIS; Descutner \& Thelen, 1991) is a 35-item questionnaire, designed to measure anxiety about intimate, romantic relationships. The fear of intimacy is defined as "the inhibited capacity of an individual, because of anxiety, to exchange thoughts and feelings of personal significance with another individual who is highly valued" (Descutner \& Thelen, 1991: p. 219). Statements (e.g. "There are people who think that I am not an easy person to get to know.") are rated on a 5-point Likert scale, ranging from 1 (not at all characteristic of me) to 5 (extremely characteristic of me). The 15 items of the scale are reversed scored.

The FIS developers proposed a unidimensional factor structure (Descutner \& Thelen, 1991; Sherman \& Thelen, 1996). However, a validation study in two samples, a Chinese and a US (Ingersoll, Norvilitis, Zhang, Jia, \& Tetewsky, 2008) proposed a 3-factor solution. The factors emerged were: Imagined Fear of Closeness (IFC), Imagined Openness (IO, reversed scored), and Past Fear of Closeness (PFC). This factor structure was used in the present study. Reported internal consistency reliability (Ingersoll et al., 2008) was $\alpha=.92$ for the U.S. sample and $\alpha=.88$ for the Chinese sample (Ingersoll, Norvilitis, Zhang, Jia, \& Tetewsky, 2008). Descutner and Thelen (1991) reported test-retest reliability of .89 over a 1-month period. In this study, internal consistency was $\alpha=.93$.

\section{Demographics}

Participants completed a demographics questionnaire with questions addressing: age, gender, religion, level of education, employment status, and whether the respondent was partnered or un-partnered and finally the length of their interpersonal relationship.

\section{Procedure}

Participants were an ad hoc sample using network sampling. More specifically 40 postgraduate students recruited about 3 - 4 adults to voluntarily participate in the study. Before test-battery completion volunteers were briefed on the nature and purpose of the study by research team members and informed consent was signed, protecting anonymity and confidentiality of the responses during the data collection, analysis and storage. The option to withdraw from the study at any time was explicitly offered to volunteers. Then they completed a paper and pencil test-battery. The required completion time was approximately $15 \mathrm{mi}$ nutes. Nor participants neither students received any rewards.

\section{Software used}

Analyses were conducted using R (Development Core Team, 2018), Mplus 7 (Muthen \& Muthen, 2012) and SPSS .25 (IBM, 2017). R packages used were (a) Package "psych" (Revelle, 2018) and MVN version 5.5 (Korkmaz, Goksuluk, \& Zararsiz, 2018).

\section{Results}

\section{Data Screening and distributional characteristics}

One-hundred and forty-eight participants took part in the study. There were 
no missing values in the dataset because volunteers were cautioned to answer all questions during recruitment.

Prior to the CFA analysis, the data were evaluated for multivariate outliers. Evaluation of Mahalanobis distances (Mahalanobis, 1936; Rousseeuw and Van Zomeren, 1990) for each case of the dataset (Kline, 2016; Pallant, 2016; Tabachnick \& Fidell, 2013) showed there were nine multivariate outliers, $p<.001$. All outliers were included in subsequent analyses because they were not data entry errors thus, the exclusion was unsupported (see cases in Figure 2). The final dataset was $N=148$.

The means, standard deviations, skew and kurtosis of each IRAQ item are shown in Table 1 ( $p s>.001$ ). Most indicator means were around 2.19, corresponding to a scale point between "rarely true" and "sometimes true".

Additionally, univariate normality was estimated with the following five tests: 1) Kolmogorov-Smirnov (Massey, 1951) with Lilliefors significance correction; 2) Shapiro-Wilk (Shapiro and Wilk 1965); 3) Shapiro-Francia (Shapiro \& Francia, 1972; Royston, 1983); 4) Anderson-Darling; 5) Cramer-von Mises. The $p$ values of all five univariate normality tests for the nine IRAQ observed variables were significant, $p<.001$.

Multivariate normality was evaluated with the following six tests: 1) Mardia's multivariate skewness test (Mardia, 1970); 2) Mardia's multivariate kurtosis test (Mardia, 1970); 3) Henze-Zirkler's consistent test (Henze \& Zirkler, 1990); 4) Doornik-Hansen omnibus test (Doornik \& Hansen, 2008); 5) E-statistic and 6) Royston. The null hypothesis was rejected in all tests with $p$ values $<.0001$. See the results of all normality tests in Table 1.

Confirmatory Factor Analysis (CFA)

The hypothesized model is overidentified, with $27 d f$. The ratio of cases to observed variables is $16: 1$ and the ratio of cases to estimated parameters is $8: 1$.

A robust maximum likelihood minimization function was used as an estimator (robust ML; see Yuan \& Bentler, 2000). Goodness of fit was evaluated with the Standardized Root Mean Square Residual (SRMR), Root Mean Square Error of Approximation (RMSEA; Steiger \& Lind, 1980) and its 90\% confidence interval (90\% CI), Comparative Fit Index (CFI; Bentler, 1990), and the Tucker-Lewis Index (TLI; Tucker \& Lewis, 1973). As suggested by Hu and Bentler (1999), acceptable model fit was defined by the following criteria: RMSEA $(\leq .06,90 \% \mathrm{CI}$ $\leq .06, \operatorname{SRMR}(\leq .08)$, CFI ( $\geq .95)$, and TLI $(\geq .95)$.

Based on theory and prior evidence the following two models were tested. MODEL 1 is the single factor model proposed in the literature (Brown et al., 2014; Li \& Rohner, 2014; Naz \& Kausar, 2015). MODEL 2 is a variation of MODEL 1 with error covariances added in item 1 with item 8 and item 2 with item 3 (see also Naz \& Kausar, 2015 for a similar approach). Covariances were based on the semantic similarity of the items, item 1 (afraid) is expected to have an error covariance with item 8 (nervous) and likewise item 2 (upset) with item 3 (anxious). 
Table 1. Univariate descriptive statistics of IRAQ measured variables, univariate and multivariate normality tests.

\begin{tabular}{|c|c|c|c|c|c|c|c|c|c|}
\hline \multirow{2}{*}{ Statistic $(N=148)$} & \multicolumn{9}{|c|}{ Univariate Descriptive Statistics for IRAQ measured variables } \\
\hline & IRAQ1 & IRAQ2 & IRAQ3 & IRAQ4 & IRAQ5 & IRAQ6 & IRAQ7 & IRAQ8 & IRAQ9 \\
\hline Mean $(M)$ & 2.18 & 2.49 & 2.76 & 2.02 & 1.87 & 2.64 & 1.55 & 2.41 & 1.81 \\
\hline Standard Deviation $(S D)$ & .91 & .87 & .85 & .84 & .91 & .92 & .81 & .85 & .83 \\
\hline Skew & .12 & -.32 & -.71 & .37 & .63 & -.37 & 1.37 & -.14 & .65 \\
\hline Kurtosis & -1.03 & -.71 & -.01 & -.69 & -.68 & -.70 & 1.02 & -.73 & -.51 \\
\hline \multicolumn{10}{|c|}{ Univariate Normality Tests } \\
\hline Kolmogorov-Smirnov & .21 & .29 & .35 & .23 & .26 & .28 & .37 & .25 & .26 \\
\hline Shapiro-Wilk & .86 & .85 & .80 & .85 & .81 & .86 & .69 & .86 & .81 \\
\hline Shapiro-Francia & .86 & .85 & .81 & .85 & .82 & .86 & .70 & .87 & .81 \\
\hline Anderson-Darling & 8.59 & 10.19 & 13.96 & 9.22 & 11.06 & 9.14 & 19.51 & 9.10 & 11.52 \\
\hline Cramer-von Mises & 1.35 & 1.87 & 2.87 & 1.53 & 1.74 & 1.72 & 3.57 & 1.62 & 1.84 \\
\hline \multicolumn{10}{|c|}{ Multivariate Normality Tests } \\
\hline Mardia's Skew & \multicolumn{3}{|c|}{$326.06, p<.0001$} & \multicolumn{2}{|c|}{ Doornik-Hansen } & \multicolumn{4}{|c|}{$49.54(18), p<.0001$} \\
\hline Mardia's kurtosis & \multicolumn{3}{|c|}{$5.12, p<.0001$} & \multicolumn{2}{|c|}{ E-statistic } & \multicolumn{4}{|c|}{$2.51, p<.0001$} \\
\hline Henze-Zirkler's & \multicolumn{3}{|c|}{$1.33, p<.0001$} & \multicolumn{2}{|c|}{ Royston } & \multicolumn{4}{|c|}{$438.25, p<.0001$} \\
\hline
\end{tabular}

Note. All univariate normality tests were significant at $p<.001$ level.

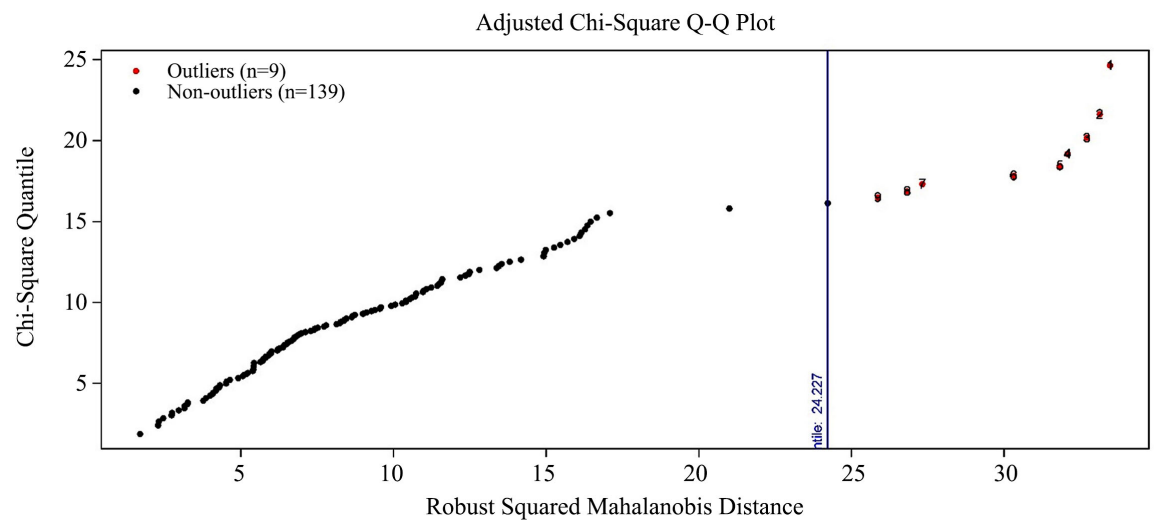

Figure 2. Adjusted Chi-Square Q-Q plot of robust squared mahalanobis distance.

Regarding model fit, MODEL1 had inadequate fit. MODEL 2, (a variation of MODEL 1 with error covariances added) had an adequate fit (see details in Table 2). Standardized parameter estimates from this solution are presented in Figure 3. The overall size of the factor loadings of the items were adequate $(\lambda$ $=.506-.820)$, indicating a well-defined factor of interpersonal anxiety.

\section{Multiple Indicators Multiple Causes modeling (MIMIC)}

CFA with covariates or MIMIC modeling (c.f. Muthen, 1989; Jöreskog \& Goldberger, 1975) offers an alternative technique for evaluating invariance of indicators and latent means in multiple groups, by regressing them onto covariates denoting group membership. Additionally, MIMIC models can handle small samples, even of $N=150$ (Brown, 2015: pp. 273-274). 


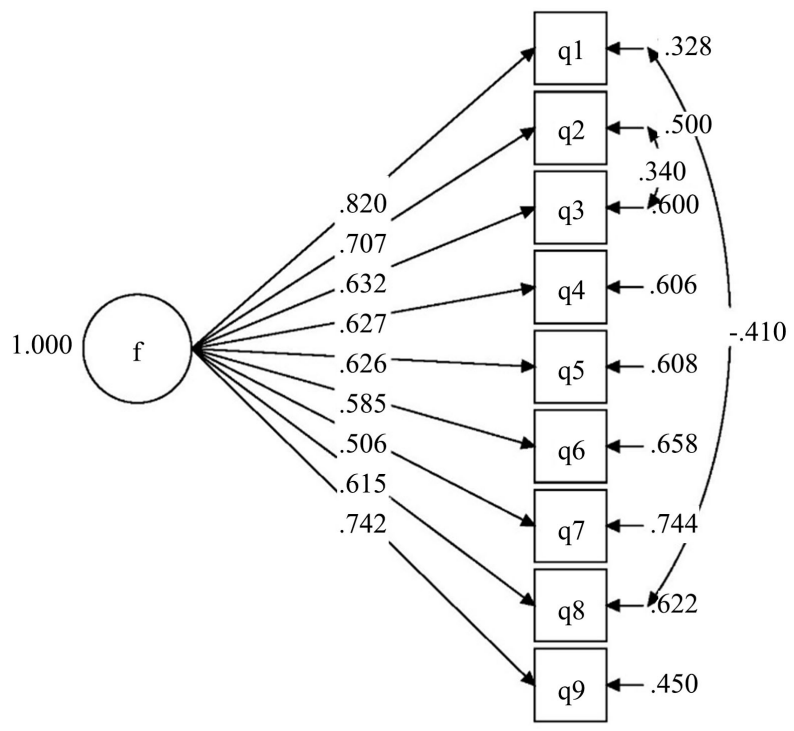

Figure 3. A path diagram of the standardized solution for the optimal IRAQ model. Note. All freely estimated unstandardized parameters were statistically significant at $p<.001$ level. MLR estimator was used.

Table 2. Goodness of fit statistics and information criteria for the IRAQ Models specified in the CFA.

\begin{tabular}{ccccccccc}
\hline Model $(N=148)$ & Chi-Square $^{*}$ df & CFI & TLI & RMSEA & $\begin{array}{c}\text { RMSEA } \\
\text { Lower CI }\end{array}$ & $\begin{array}{c}\text { RMSEA } \\
\text { Higher CI }\end{array}$ & SRMR \\
\hline $\begin{array}{c}\text { MODEL 1 } \\
\begin{array}{c}\text { Brown et al., 2014) } \\
\text { Single factor }\end{array}\end{array}$ & 65.28 & 27 & .908 & .876 & .098 & .066 & .129 & .056 \\
$\begin{array}{c}\text { MODEL 2 Single factor } \\
\text { with error Cov. }\end{array}$ & $\mathbf{4 1 . 0 6}$ & $\mathbf{2 5}$ & .960 & .945 & .064 & .026 & .099 & .048 \\
\hline
\end{tabular}

Note. ${ }^{*} p<.01$. Estimator $=$ MLR; Bold indicates optimal fit. $\mathrm{df}=$ Degrees of freedom; CFI $=$ Comparative Fit Index; TLI $=$ Tucker-Lewis index; RMSEA $=$ Root Mean Square Error of Approximation; $\mathrm{CI}=$ Confidence Interval; SRMR = Standardized Root Mean Square Residual.

The single factor model with error covariances was used as a baseline model because it was the optimal model in the preceding CFA. Next, the following three covariates (indicating group membership) were added to examine their effects on latent means and indicator intercepts: 1 ) Between age and interpersonal anxiety ( 1 = participants with aged $\geq 25$ years, $N=62$ or $42 \%$; $0=$ participants aged $\leq 24$ years, $N=86$ or $58 \%$ ); 2 ) Between gender and interpersonal anxiety (1 = male participants, $N=74 ; 2=$ female participants, $N=74)$ and 3) Between relationship status and interpersonal anxiety $(1=$ partnered participants, $N=74 ; 2$ = un-partnered participants; $N=74$ ). The results showed that this MIMIC model provided an acceptable fit to the data: $\chi^{2}(49)=70.32$, SRMR $=.051$, RMSEA $=.055(90 \% \mathrm{CI}=.020-.081$, TLI $=.952, \mathrm{CFI}=.939$ (see the MIMIC model in Figure 4). Two potential sources of invariance were tested: the equivalence of factor means across groups (absence of population heterogeneity) and the equivalence of IRAQ indicator intercepts Q1-Q9 (measurement invariance). 


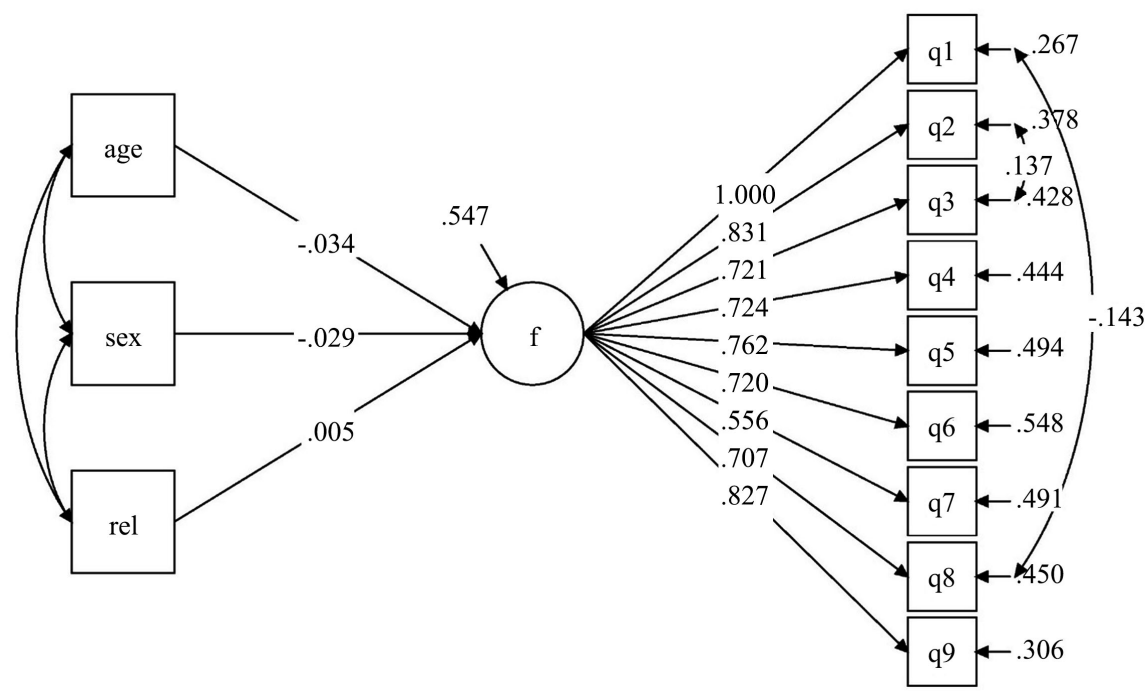

Figure 4. Path diagram of the MIMIC Model tested. This is an ICM-CFA model on which the covariates of gender, age ( $\geq 25$ and $\leq 24$ years), and relationship status (partnered, un-partnered) were added. Note. All freely estimated unstandardized parameters were statistically significant at $p<.001$ level. MLR estimator was used.

Population heterogeneity: The effect of age on the latent factor of IRAQ (interpersonal anxiety) is negative and not statistically significant, $(-.034, p=.791)$. The effect of gender on the latent factor of interpersonal anxiety is negative and not statistically significant $(-.029, p=.824)$. The effect of relationship status on the latent factor of interpersonal anxiety is positive and not statistically significant $(.005, p=.966)$.

Measurement Invariance: After examining the effect of gender, age and relationship status covariates on the latent factor of interpersonal anxiety, whether these covariates directly affected the observed endogenous indicators Q1-Q9 was examined. Results showed that the direct effect of age on IRAQ observed endogenous indicators (Q1-Q9) was not significant. Similarly, the direct effect of gender on IRAQ observed endogenous indicators (Q1-Q9) was also not significant. Finally, the direct effect of relationship status on indicators Q1-Q9 was not significant.

\section{Internal Consistency Reliability}

We evaluated the reliability and validity of IRAQ using Cronbach's alpha coefficient (Cronbach, 1951) to assess the internal consistency of item responses. Alpha values $\geq .70$ are considered adequate (Hair, Black, Babin, \& Anderson, 2010) and $\geq .80$ satisfactory (Nunnally \& Berstein, 1994). The internal reliability for all 9 items of IRAQ was $\alpha=.87$. Alpha would not improve if any item was deleted with alphas ranging from (.843, item 1) to .865 (Item 7).

\section{Convergent Validity}

A correlation analysis was carried out to examine the relationship of Interpersonal Relationship Anxiety Questionnaire (IRAQ; Rohner (2012) with 1) Fear of Intimacy Scale (FIS; Descutner \& Thelen, 1991); 2) the two versions (Mother and Father) of the Adult PARQ, Short Form (Roher \& Khaleque, 2005a). The 
correlations of IRAQ with FIS were significant, but low to moderate in magnitude, ranging from $r_{s}(146)=.18, p<.001(\mathrm{PFC})$ to $r_{\mathrm{s}}(146)=.35, p<.001$ (IO). IRAQ was significantly and moderately correlated with FIS Total $r_{s}(146)=.33, p$ $<.001$. See Table 3 for details. There was significant moderate to strong correlations, between IRAQ and the Mother Version of Adult PARQ, ranging from $r_{\mathrm{s}}(146)=.35, p<.001$ (reversed Warmth/Affection) to $r_{\mathrm{s}}(146)=.46, p<.001$ (Indifference/Neglect). The correlations between IRAQ and the Father Version of Adult PARQ were also moderate to strong, ranging from $r_{s}(146)=.30, p$ $<.001$ (reversed Warmth/Affection) to $r_{\mathrm{s}}(146)=.51, p<.001$ (Hostility/ Aggression). The above interpretations of the magnitude of correlation adopted the criteria set by Cohen (1988). Table 3 presents all the results of the correlation analysis. Correlations of IRAQ are also presented graphically in Figure 5.

\section{Description of IRAQ scores}

Participants on average scored $M=19.73$ ( $S D=5.44$ ). Score range is 9 - 36 . One-half of the participants scored $\leq 20.00,25 \%$ scored $\leq 16.00$ and $75 \%$ scored $\leq 23.50$.

\section{Discussion}

The focus of this work was to evaluate the psychometric properties of the Interpersonal Relationship Anxiety Questionnaire (IRAQ) by Rohner (2012) in Greek adults of the general population. Specifically, research objectives were the following: 1) To evaluate invariance for item intercepts and latent factor means using Multiple Indicators Multiple Causes modeling (MIMIC), controlling for the

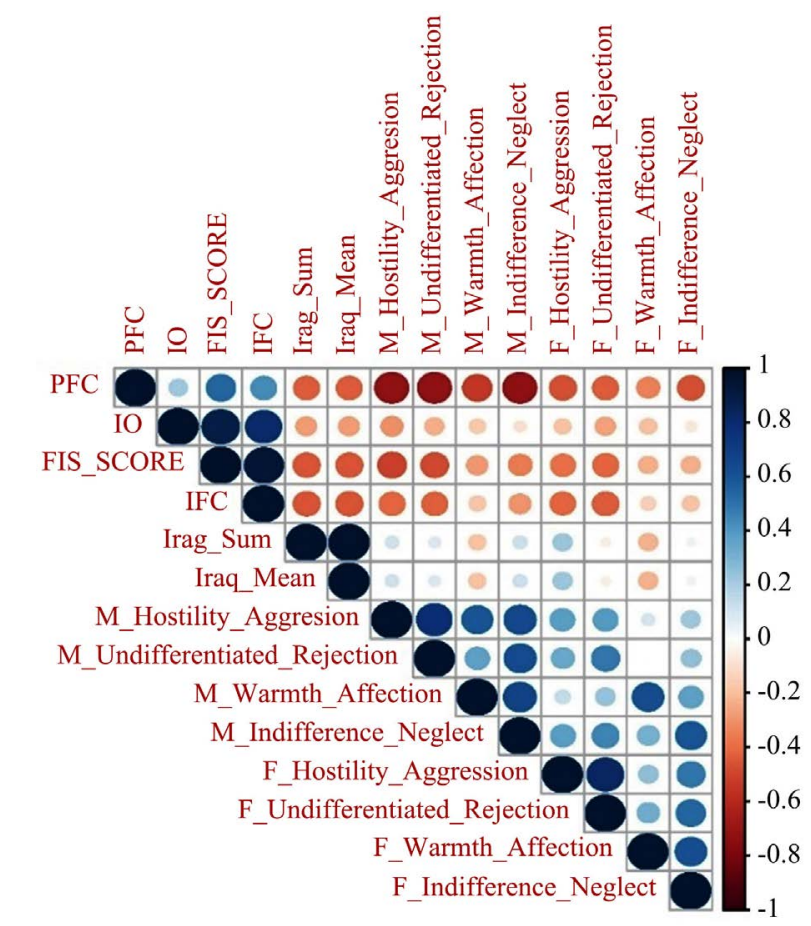

Figure 5. Graphical representation of IRAQ correlation coefficients (Spearman's rho) with FIS and Adult PARQ. 
Table 3. Bivariate correlations between IRAQ and other variables.

\begin{tabular}{cc}
\hline$N=148$ & Spearman's rho \\
\hline Fear of Intimacy Scale (FIS) & .25 \\
Imagined Fear of Closeness (IFC) & .35 \\
Imagined Openness (IO; Reversed) & .18 \\
Past Fear of Closeness (PFC) & .33 \\
FIS Total & .35 \\
Adult PARQ, Mother & .42 \\
Warmth/ Affection (Reversed) & .46 \\
Hostility/ Aggression & .39 \\
Indifference/ Neglect & .31 \\
Undifferentiated Rejection & .36 \\
Adult PARQ, PARQ Father & .36 \\
Warmth/ Affection (Reversed) & .36 \\
Hostility/ Aggression & .36 \\
Indifference/ Neglect & \\
Undifferentiated Rejection & .36 \\
\hline
\end{tabular}

Note. All correlation coefficients were significant at $p<.001$. FIS items allocation per factor: $\operatorname{IFC}=1,2,4,5$, $9,11,12,13,15,16,20,23,24,26,28 ; \mathrm{IO}=3,6,7,8,10,14,17,18,19,21,22,25,27,29,30$; $\mathrm{PFC}=31,32$, $33,34,35$.

effects of gender, age and relationship status. 2) To evaluate internal consistency reliability (a). 3) To examine the relation of IRAQ with the construct of fear of intimacy and reflections of perceived parental rejection (both by mother and father), evidencing Convergent Validity further. Instruments used to check convergent validity was the Fear of Intimacy Scale (FIS; Descutner \& Thelen. 1991) and the Parental Acceptance-Rejection Questionnaire (Adult PARQ, short form by Roher \& Khaleque, 2005a). For the later, both the Mather and the father version were included to check reflected rejection of adult participants during their childhood, by both parents (see Rohner, 1975, 2004). The 3-faced construct validation method (Kyriazos, 2018a) could not be implemented because of the sample size (see also Kyriazos et al., 2018; Kyriazos 2018a, 2018b).

The main findings suggested that: 1) the unidimensional factor structure of IRAQ is tenable in the Greek cultural context. 2) a MIMIC model was tested using the optimal IRAQ CFA model controlling for the effect of gender, age and relationship status on latent factor means and indicator intercepts and no significant effects were found. This is indicative of population heterogeneity and measurement invariance (see Muthen, 1989; Timothy Brown, 2015 and Wang \& Wang, 2012). 3) Internal consistency reliability was adequate. 4) Significant correlations of IRAQ with fear of intimacy (Descutner \& Thelen, 1991) and perceived reflected parental rejection (Rohner, 1975, 2004) suggested convergent validity. 5) Description of IRAQ scores followed. 
Examining findings in more detail, data were first checked for data entry accuracy, and the distributions of the IRAQ observed variables were examined to see if the assumption of univariate and multivariate normality was violated. The CFA was performed to examine if the unidimensional structure of IRAQ is confirmable in this Greek Adult sample of the general population. A total of two alternative CFA models were examined. First, the single factor structure of IRAQ was tested with no error covariances in the nine observed variables. This model had an inadequate fit. Then, in line with other works found in the literature (e.g. Naz \& Kausar, 2015) two error variances were added; one in item 1 (afraid) with item 8 (nervous) and a second in item 2 (upset) with item 3 (anxious). These additions are plausible on the basis of semantic similarities of the items (Brown, 2015). Beyond semantic similarity, additional theoretical support for the covariance of these errors could be found in a proposed Negative Affect model by Mehrabian (1998) as described by Crawford \& Henry, 2004. In this model NA was conceptualized as a second-order factor with afraid and upset as two firstorder factors, thus as basic components of NA, these items are expected to have correlated error variances. Taking into account the goodness of fit statistics and the factor loadings the fit of this model was adequate. Evidence of construct validity was supported further because all fit measures reached the suggested levels of significance (Hair et al., 2010). Additionally, this single factor structure was also established in other cultural contexts, i.e. in a US women sample (Brown et al., 2014), in a Chinese sample of adolescents (Li \& Rohner, 2014), in schoolchildren from Croatia. Finally, the Urdu version of IRAQ was also found to be unidimensional, used both on a clinical and a non-clinical sample of female adolescents (Naz \& Kausar, 2015). Generally, to the best of our knowledge, the above empirical findings cannot be compared to similar results, due to a lack of empirical literature on IRAQ factor structure in the general adult population.

Regarding sample power of the model, the ratio of cases to observed variables was above the sample-to-variable acceptability threshold ranging from 5:1 - 10:1 for up to $\mathrm{N}=300$ (DeVellis, 2017; Tinsley \& Tinsley, 1987). Respectively, the ratio of sample to estimated parameters was equally satisfactory (Kline, 2016). Hence, sample power was adequate taking into account the high-reliability coefficients of IRAQ (DeVellis, 2017; Kyriazos, 2018b; Ullman, 2013).

Moreover, the optimal CFA model was used as a measurement model in a CFA with covariates modeling (MIMIC). The covariates of gender, age, and relationship status were tested for direct effects on the latent factor means and on indicator intercepts. The MIMIC model had an adequate fit and thus potential sources of invariance in latent means and indicator intercepts were tested (Brown, 2015). First, by adding the covariate onto the interpersonal anxiety the equivalence of factor means was evaluated across groups (population heterogeneity). A significant direct effect of either the covariate of age, gender or relationship status on the interpersonal anxiety latent factor would equal population heterogeneity. This essentially would mean that mean interpersonal anxiety is different at different levels of the covariates (Brown, 2015; Wang \& Wang, 2012), 
however, no statistically significant effects were found. The direct effects of the covariates on social anxiety were not statistically significant. Thus, no population heterogeneity was found for interpersonal anxiety as measured by IRAQ. In practice, this means that the mean of the interpersonal anxiety latent factor is not different at different levels of the three covariates tested (age, sex, relationship status). Respondents' gender, aged or being partnered/un-partnered does not influence factor means (see Brown, 2015) and Wang and Wang (2012) for details.

Second, by MIMIC modeling, we can also investigate if these three covariates have a direct impact on the indicators of IRAQ Q1-Q9. A significant direct effect of any of these covariates on an indicator intercept would suggest that the value of the indicator differs by the values of the covariate, if the social anxiety latent factor is held constant (i.e. Differential item functioning; Muthen, 1989; Brown, 2015). However, no salient direct effects were present. This suggests there is measurement invariance between the groups, i.e. the value of Q1-Q9 does not differ by the values of any of the three covariates if the social anxiety latent factor is held constant. That is, when the factor is held constant irrespectively of the respondent's gender, age or relationship status, the intercepts of each of the nine IRAQ indicators show measurement invariance when latent factor mean does not change (Brown, 2015).

Internal consistency reliability was significant. Finally, correlation analysis that followed showed that IRAQ is significantly correlated with fear of intimacy (Descutner \& Thelen, 1991) and perceived parental rejection during childhood (Rohner, 1975, 2004; Rohner \& Rohner, 1984). This is also in line with other empirical findings (Naz \& Kausar, 2015; Vulic-Prtoric \& Glavak-Tkalic, 2016). Regarding IRAQ scores, comparisons are not possible due to the absence of similar empirical findings. Specifically, a search of the existing literature revealed no general adult population norms.

\section{Conclusion}

The basic finding and strength of the present study are that the unidimensional structure of IRAQ is first validated in the general adult population. A second prominent finding is that interpersonal anxiety mean is not different at various levels of the indicators irrespectively of the gender, age and relationship status of the respondent. The same is true for indicator intercepts if a latent factor is held constant. This excludes the possibility of measurement biased when using IRAQ (Damasio \& Koller, 2015). Reliability and validity results were also adequate.

However, the present study has certain limitations. The most obvious is the marginally acceptable sample size and the second is the absence of additional measures to test convergent and discriminant validity because Greek versions for various measures are often unavailable. However, sample power was not bad and the model had sufficient psychometric properties (model fit, factor loadings, and reliability coefficients) to counterbalance small sample size (DeVellis, 2017). Nev- 
ertheless, results must be replicated in a larger sample. Another problem could potentially be the use of error covariances, especially in combination with the marginally acceptable sample size and no cross-validation of the results followed (Byrne, 2012; Brown, 2015). However, the obvious content similarity of the covaried items offsets these shortcomings (Brown, 2015). Future research should replicate the current study to samples including more instruments, more age groups, and different cultures. Considering all the above findings IRAQ is a valid and reliable measure of interpersonal anxiety, with reliable psychometric properties exposing measurement invariance and absence of heterogeneity for the Greek adult population.

\section{Conflicts of Interest}

The authors declare no conflicts of interest regarding the publication of this paper.

\section{References}

Baldwin, M. W. (1992). Relational Schemas and the Processing of Societal Information. Psychological Bulletin, 112, 461-484. https://doi.org/10.1037/0033-2909.112.3.461

Bartholomew, K., \& Horowitz, L. M. (1991). Attachment Styles among Young Adults: A Test of a Four-Category Model. Journal of Personality and Social Psychology, 61, 226244. https://doi.org/10.1037/0022-3514.61.2.226

Baumeister, R., \& Leary, M. R. (1995). The Need to Belong: Desire for Interpersonal Attachments as a Fundamental Human Motivation. Psychological Bulletin, 117, 497-529. https://doi.org/10.1037/0033-2909.117.3.497

Beidel, D. C., \& Turner, S. M. (1998). Shy Children, Phobic Adults. Washington DC: American Psychological Association. https://doi.org/10.1037/10285-000

Bernier, A., \& Dozier, M. (2002). The Client-Counselor Match and the Corrective Emotional Experience: Evidence from Interpersonal and Attachment Research. Psychotherapy: Theory/Research/Practice/Training, 39, 32-43.

https://doi.org/10.1037/0033-3204.39.1.32

Bowlby, J. (1969). Attachment. Attachment and Loss (Vol. 1.). New York: Basic Books.

Bowlby, J. (1980). Loss: Sadness \& Depression. Attachment and Loss (Vol. 3). London: Hogarth Press.

Bowlby, J. (1988). Attachment, Communication, and the Therapeutic Process. In $A S e-$ cure Base: Parent-Child Attachment and Healthy Human Development (pp. 137-157). Milton Park, Abingdon: Taylor \& Francis Group.

Brook, C. A., \& Schmidt, L. A. (2008). Interpersonal Anxiety Disorder: A Review of Environmental Risk Factors. Neuropsychiatric Disease and Treatment, 4, 123-143. https://doi.org/10.2147/NDT.S1799

Brown, M. C., Orcel, L., Flynn, K., Galioto, A., Hodge, S., \& Parsons, K. (2014). An Investigation of the Psychometric Properties of the Interpersonal Relationships Anxiety Questionnaire. Moldova: The 5th International Conference on Interpersonal Acceptance and Rejection.

Brown, T. A. (2015). Confirmatory Factor Analysis for Applied Research (2nd ed.). New York: Guilford Publications.

Brown, T. A., Chorpita, B. F., \& Barlow, D. H. (1998). Structural Relationships among 
Dimensions of the DSM-IV Anxiety and Mood Disorders and Dimensions of Negative Affect, Positive Affect, and Autonomic Arousal. Journal of Abnormal Psychology, 107, 179-192. https://doi.org/10.1037/0021-843X.107.2.179

Clark, D. M., \& Wells, A. (1995). Acognitive Model of Social Phobia. In R. G. Heimberg, M. R. Liebowitz, D. A. Hope, \& F. R. Scheier (Eds.), Social Phobia: Diagnosis, Assessment, and Treatment (pp. 69-93). New York: Guilford Press.

Comunian, A. L., \& Gielen, U. (2000). International Perspectives on Human Development. Berlin, Germany: Pabst Science Publishers.

Conway, A. M., Tugade, M. M., Catalino, L. I., \& Fredrickson, B. (2013). The Broaden-and Build Theory of Positive Emotions: Form, Function, and Mechanisms. In S. A. David, I. Boniwell, \& A. Conley Ayers (Eds.), The Oxford Handbook of Happiness (pp. 17-34). Oxford, UK: Oxford University Press. https://doi.org/10.1093/oxfordhb/9780199557257.013.0003

Crawford, J. R., \& Henry, J. D. (2004). The Positive and Negative Affect Schedule (PANAS): Construct Validity, Measurement Properties and Normative Data in a Large Non-Clinical Sample. British Journal of Clinical Psychology, 43, 245-265.

Cronbach, L. J. (1951). Coefficient Alpha and the Internal Structure of Tests. Psychometrika, 16, 297-334. https://doi.org/10.1007/BF02310555

Damasio, B., \& Koller, S. H. (2015). Meaning in Life Questionnaire: Adaptation Process and Psychometric Properties of the Brazilian Version. Revista Latinoamericana de Psicología, 47, 185-195. https://doi.org/10.1016/j.rlp.2015.06.004

Davis, D. (1982). Determinants of Responsiveness in Dyadic Interaction. In W. Ickes, \& E. S. Knowles (Eds.), Personality, Roles, and Social Behavior (pp. 85-139). New York: Springer-Verlag. https://doi.org/10.1007/978-1-4613-9469-3_4

Descutner, C. J., \& Thelen, M. H. (1991). Development and Validation of a Fear-of-Intimacy Scale. Psychological Assessment, 3, 218-225.

https://doi.org/10.1037/1040-3590.3.2.218

DeVellis, R. F. (2017). Scale Development: Theory and Applications (4th ed.). Thousand Oaks, CA: Sage.

Diener, E., \& Seligman, M. E. P. (2002). Very Happy People. Psychological Science, 13, 81-84. https://doi.org/10.1111/1467-9280.00415

Epstein, S. (1994). Integration of the Cognitive and the Psychodynamic Unconscious. American Psychologist, 49, 709-724. https://doi.org/10.1037/0003-066X.49.8.709

Erikson, E. H. (1968). Identity: Youth and Crisis. New York: Norton.

Ferssizidis, P., Kashdan, T. B., Marquart, R., \& Steger, M. F. (2013). Positive Psychological Experiences and Psychopathology: A Self-Regulatory Perspective. In S. A. David, I. Boniwell, \& A. Conley Ayers (Eds.), The Oxford Handbook of Happiness (pp. 101-118). Oxford: Oxford University Press.

https://doi.org/10.1093/oxfordhb/9780199557257.013.0008

Festa, C. C., \& Ginsburg, G. S. (2011). Parental and Peer Predictors of Interpersonal Anxiety in Youth. Child Psychiatry and Human Development, 42, 291-306.

https://doi.org/10.1007/s10578-011-0215-8

Fredrickson, B. (2013). Love 2.0: How Our Supreme Emotion Affects Everything We Think, Do, Feel, and Become. New York: Hudson Street Press.

Garber, J., \& Flynn, C. (2001). Vulnerability to Depression in Childhood and Adolescence. In R. E. Ingram, \& J. M. Price (Eds.), Vulnerability to Psychopathology: Risk across the Lifespan (pp. 175-225). New York: Guilford Press.

Giotsa, A. (2015). The Interpersonal Relationship Anxiety Questionnaire, Greek Version. 
Greece: University of Ioannina.

Giotsa, A., \& Touloumakos, A. (2014). “They Accept Me; They Accept Me Not”: Psychometric Properties of the Greek Version of Child Parental Acceptance-Rejection Questionnaire-Short Form. Journal of Family Issues, 37, 1-18.

Giotsa, A., Kyriazos, T. A., \& Mitrogiorgou, E. (2018). Parental Acceptance-Rejection and Interpersonal Anxiety in Young Adults. Hellenic Journal of Psychology, 15, 138-150.

Giotsa, A., Stalikas, A., Kyriazos, T., \& Zergiotis, A. (2018). Social Anxiety in Greek Adults. Athens, Greece: The 7th International Congress on Interpersonal Acceptance \& Rejection.

Gomez, R., \& Rohner, R. P. (2011). Tests of Factor Structure and Measurement Invariance in the US and Australia Using the Adult Version of the Parental Acceptance Rejection Questionnaire. Cross Cultural Research, 45, 267-285. https://doi.org/10.1177/1069397111403111

Hair, J., Black, W., Babin, B., \& Anderson, R. (2010). Multivariate Data Analysis (7th ed.). Upper Saddle River, NJ: Prentice-Hall, Inc.

Hartman, L. M. (1983). A Metacognitive Model of Social Anxiety: Implications for Treatment. Clinical Psychology Review, 3, 435-456. https://doi.org/10.1016/0272-7358(83)90023-5

Hazan, C., \& Shaver, P. R. (1987). Romantic Love Conceptualized as an Attachment Process. Journal of Personality and Social Psychology, 52, 511-524. https://doi.org/10.1037/0022-3514.52.3.511

Hofstede, G. (2001). Culture's Consequences: Comparing Values, Behaviors, Institutions, and Organizations across Nations (2nd ed.). Thousand Oaks, CA: Sage.

Hope, D. A., Gansler, D. A., \& Heimberg, R. G. (1989). Attentional Focus and Causal Attributions in Social Phobia: Implications from Social Psychology. Clinical Psychology Review, 9, 49-60. https://doi.org/10.1016/0272-7358(89)90046-9

Hummel, R. M., \& Gross, A. M. (2001). Socially Anxious Children: An Observational Study of Parent-Child Interaction. Child and Family Behavior Therapy, 23, 19-40. https://doi.org/10.1300/J019v23n03_02

IBM Corporation (2017). IBM SPSS Statistical Software, Release 25. New York: IBM Corporation.

Ingersoll, T. S., Norvilitis, J. M., Zhang, J., Jia, S., \& Tetewsky, S. (2008). Reliability and Validity of the Fear of Intimacy Scale in China. Journal of Personality Assessment, 90, 270-279. https://doi.org/10.1080/00223890701885019

Kashdan, T. B. (2007). Social Anxiety Spectrum and Diminished Positive Experiences: Theoretical Synthesis and Meta-Analysis. Clinical Psychology Review, 27, 348-365. https://doi.org/10.1016/j.cpr.2006.12.003

Kashdan, T. B., \& Collins, R. L. (2010). Social Anxiety and the Experience of Positive Emotions and Anger in Everyday Life: An Ecological Momentary Assessment Approach. Anxiety, Stress, \& Coping, 23, 259-272. https://doi.org/10.1080/10615800802641950

Kashdan, T. B., \& Roberts, J. E. (2004a). Trait and State Curiosity in the Genesis of Intimacy: Differentiation from Related Constructs. Journal of Social and Clinical Psychology, 23, 792-816. https://doi.org/10.1521/jscp.23.6.792.54800

Kashdan, T. B., \& Roberts, J. E. (2004b). Social Anxiety's Impact on Affect, Curiosity, and Social Self-Efficacy during a High Self-Focus Social Threat Situation. Cognitive Therapy and Research, 28, 119-141. https://doi.org/10.1023/B:COTR.0000016934.20981.68

Kashdan, T. B., Ferssizidis, P., Farmer, A. S., Adams, L. M., \& McKnight, P. E. (2013). 
Failure to Capitalize on Sharing Good News with Romantic Partners: Exploring Positivity Deficits of Socially Anxious People with Self-Reports, Partner-Reports, and Behavioral Observations. Behaviour Research and Therapy, 51, 656-668.

https://doi.org/10.1016/j.brat.2013.04.006

Kessler, R. C., McGonagle, K. A., Zhao, S., Nelson, C. B., Hughes, M., Eshleman, S. et al. (1994). Lifetime and 12-Month Prevalence of DSM-III-R Psychiatric Disorders in the United States: Results from the National Comorbidity Survey. Archives of General Psychiatry, 51, 8-19. https://doi.org/10.1001/archpsyc.1994.03950010008002

Khaleque, A., \& Rohner, R. P. (2012). Transnational Relations between Perceived Parental Acceptance and Personality Dispositions of Children and Adults: A Meta-Analytic Review. Personality and Social Psychology Review, 16, 103-115. https://doi.org/10.1177/1088868311418986

Kiesler, D. J. (1983). The 1982 Interpersonal Circle: A Taxonomy for Complementarity in Human Transactions. Psychological Review, 90, 185-214. https://doi.org/10.1037/0033-295X.90.3.185

Kiesler, D. J. (1996). Contemporary Interpersonal Theory and Research: Personality, Psychopathology and Psychotherapy. New York: Wiley.

Kline, R. B. (2016). Principles and Practice of Structural Equation Modeling (4th ed.). New York: The Guilford Press.

Korkmaz, S., Goksuluk, D., \& Zararsiz, G. (2018). MVN: An R Package for Assessing Multivariate Normality ( $R$ Package). Edirne, Turkey: Trakya University. http://opensoft.turcosa.com.tr/MVN/

Kyriazos, T. A. (2018a). Applied Psychometrics: The 3-Faced Construct Validation Method, a Routine for Evaluating a Factor Structure. Psychology, 9, 2044-2072.

https://doi.org/10.4236/psych.2018.98117

Kyriazos, T. A. (2018b). Applied Psychometrics: Sample Size and Sample Power Considerations in Factor Analysis (EFA, CFA) and SEM in General. Psychology, 9, 2207-2230. https://doi.org/10.4236/psych.2018.98126

Kyriazos, T. A., Stalikas, A., Prassa, K., Galanakis, M., Flora, K., \& Chatzilia, V. (2018). The Flow Short Scale (FSS) Dimensionality and What MIMIC Shows on Heterogeneity and Invariance. Psychology, 9, 1357-1382. https://doi.org/10.4236/psych.2018.96083

La Greca, A. M., \& Lopez, N. (1998). Interpersonal Anxiety among Adolescents: Linkages with Peer Relations and Friendships. Journal of Abnormal Child Psychology, 26, 83-94. https://doi.org/10.1023/A:1022684520514

Leary, M. R. (2004). The Sociometer, Self-Esteem, and the Regulation of Interpersonal Behavior. In R. F. Baumeister, \& K. D. Vohs (Eds.), Handbook of Self-Regulation: Research Theory, and Applications (pp. 373-391). New York: Guildford Press.

Li, X., \& Rohner, P. R. (2014). Psychometric Properties of Interpersonal Relationship Anxiety Questionnaire (IRAQ). Under Preparation.

Mehrabian, A. (1998). Comparison of the PAD and PANAS as Models for Describing Emotions and for Differentiating Anxiety from Depression. Journal of Psychopathology and Behavioural Assessment, 19, 331-357. https://doi.org/10.1007/BF02229025

Morris, T. L. (2001). Social Phobia. In M. W. Vasey, \& M. R. Dadds (Eds.), The Developmental Psychopathology of Anxiety (pp. 435-458). New York: Oxford University Press. https://doi.org/10.1093/med:psych/9780195123630.003.0019

Mruk, C. J. (2006). Self-Esteem Research, Theory, and Practice: toward a Positive Psychology of Self-Esteem (3rd ed.). New York: Springer.

Muthen, B. (1989). Latent Variable Modeling in Heterogeneous Populations. Psychome- 
trika, 54, 557-585. https://doi.org/10.1007/BF02296397

Muthen, L. K., \& Muthen, B. O. (2012). Mplus Statistical Software, 1998-2012. Los Angeles, CA: Muthen \& Muthen.

Naz, F., \& Kausar, R. (2015). Translation and Validation of Interpersonal Relationship Anxiety Questionnaire (IRAQ). FWU Journal of Social Sciences, 9, 118-126.

Pfeffer, C. R., Lipkins, R., Plutchik, R., \& Mizruchi, M. (1988). Normal Children at Risk for Suicidal Behavior: A Two-Year Follow-Up Study. Journal of the American Academy of Child and Adolescent Psychiatry, 27, 34-41. https://doi.org/10.1097/00004583-198801000-00006

R Development Core Team (2018). R: A Language and Environment for Statistical Computing. Vienna, Austria: R Foundation for Statistical Computing.

Rapee, R. M., \& Heimberg, R. G. (1997). A Cognitive-Behavioral Model of Anxiety in Social Phobia. Behaviour Research and Therapy, 35, 741-756. https://doi.org/10.1016/S0005-7967(97)00022-3

Reker, G. T., Peacock, E. J., \& Wong, P. T. P. (1987). Meaning and Purpose in Life and Wellbeing: A Life-Span Perspective. Journal of Gerontology, 42, 44-49. https://doi.org/10.1093/geronj/42.1.44

Revelle, W. (2018). Package Psych: Procedures for Psychological, Psychometric, and Personality Research (R Package). Evanston, IL: Northwestern University.

Rohner, R. P. (1975). They Love Me, They Love Me Not: A Worldwide Study of the Effects of Parental Acceptance and Rejection. New Haven, CT: HRAF Press.

Rohner, R. P. (1986). The Warmth Dimension: Foundations of Parental Acceptance-Rejection Theory. Beverly Hills, CA: Sage.

Rohner, R. P. (2004). The Parental “Acceptance-Rejection Syndrome”: Universal Correlates of Perceived Rejection. American Psychologist, 59, 827-840.

https://doi.org/10.1037/0003-066X.59.8.830

Rohner, R. P. (2012). The Interpersonal Relationship Anxiety Questionnaire (IRAQ). Storrs, CT: Rohner Research Publications. https://doi.org/10.1037/t20445-000

Rohner, R. P. (2014). Parental Power and Prestige Moderate the Relationship between Perceived Parental Acceptance and Offspring's Psychological Adjustment: Introduction to the International Father Acceptance-Rejection Project. Cross-Cultural Research, 48, 197-213. https://doi.org/10.1177/1069397114528295

Rohner, R. P. (2016). Introduction to Interpersonal Acceptance-Rejection Theory (IPARTheory) and Evidence. Online Readings in Psychology and Culture, 6, 1-40. https://doi.org/10.9707/2307-0919.1055

Rohner, R. P., \& Britner, P. A. (2002). Worldwide Mental Health Correlates of Parental Acceptance-Rejection: Review of Cross-Cultural and Intracultural Evidence. CrossCultural Research, 36, 16-47. https://doi.org/10.1177/106939710203600102

Rohner, R. P., \& Chaki-Sircar, M. (1988). Women and Children in a Bengali Village. Hanover, NH: University Press of New England.

Rohner, R. P., \& Cournoyer, D. E. (1994). Universals in Youths' Perceptions of Parental Acceptance and Rejection: Evidence from Factor Analyses within Eight Sociocultural Groups Worldwide. Cross-Cultural Research, 28, 371-383. https://doi.org/10.1177/106939719402800408

Rohner, R. P., \& Khaleque, A. (2002). Parental Acceptance-Rejection and Life-Span Development: A Universalist Perspective. Online Readings in Psychology and Culture, 6, $1-35$. 
Rohner, R. P., \& Khaleque, A. (2005). Handbook for the Study of Parental Acceptance and Rejection. (4th ed.) Storrs, CT: Rohner Research Publications.

Rohner, R. P., \& Khaleque, A. (2005a). Parental Acceptance-Rejection Questionnaire (PARQ): Test Manual. In Handbook for the Study of Parental Acceptance and Rejection (4th ed., pp. 43-106). Storrs, CT: Rohner Research Publications. https://doi.org/10.1037/t05824-000

Rohner, R. P., \& Khaleque, A. (2005b). Personality Assessment Questionnaire (PAR): Test Manual. In Handbook for the Study of Parental Acceptance and Rejection (4th ed., pp. 187-226). Storrs, CT: Rohner Research Publications.

Rohner, R. P., \& Rohner, E. C. (1980). Antecedents and Consequences of Parental Rejection: A Theory of Emotional Abuse. Child Abuse \& Neglect, 4, 189-198. https://doi.org/10.1016/0145-2134(80)90007-1

Rohner, R. P., Saavedra, J. M., \& Granum, E. O. (1978a). Development and Validation of the Parental Acceptance and Rejection Questionnaire: Test Manual. JSAS Catalog of Selected Documents in Psychology, 8, 7-8.

Rohner, R. P., Saavedra, J. M., \& Granum, E. O. (1978b). Development and Validation of the Personality Assessment Questionnaire: Test Manual. [Storrs, CT: University of Connecticut.

Safren, S. A., \& Heimberg, R. G. (1999). Depression, Hopelessness, Suicidality and Related Factors in Sexual Minority and Heterosexual Adolescents. Journal of Consulting and Clinical Psychology, 67, 859-886. https://doi.org/10.1037/0022-006X.67.6.859

Safren, S. A., Heimberg, R. G., Brown, E. J., \& Holle, C. (1997). Quality of Life in Social Phobia. Depression and Anxiety, 4, 126-133. https://doi.org/10.1002/(SICI)1520-6394(1996)4:3<126::AID-DA5>3.0.CO;2-E

Safren, S. A., Hollander, G., Hart, T. A., \& Heimberg, R. G. (2001). Cognitive Behavioral Therapy with Gay, Lesbian, and Bisexual Youth. Cognitive and Behavioral Practice, 8, 215-223. https://doi.org/10.1016/S1077-7229(01)80056-0

Sedikides, C., Oliver, M. B., \& Campbell, K. (1994). Perceived Benefits and Costs of Romantic Relationships for Women and Men: Implications for Exchange Theory. Personal Relationships, 1, 5-21. https://doi.org/10.1111/j.1475-6811.1994.tb00052.x

Sherman, M. D., \& Thelen, M. H. (1996). Fear of Intimacy Scale: Validation and Extension with Adolescents. Journal of Social and Personal Relationships, 13, 507-521. https://doi.org/10.1177/0265407596134002

Simpson, J. A. (1999). Attachment Theory in Modern Evolutionary Perspective. In J. Cassidy, \& P. R. Shaver (Eds.), Handbook of Attachment: Theory, Research and Clinical Applications (pp. 115-140). New York: Guilford Press.

Simpson, J. A. and Rholes, W. S. (1999). Attachment Theory and Close Relationships. New York: Guilford Press.

Steger, M. F., Beeby, A., Garrett, S., \& Kashdan, T. D. (2013). Creating a Stable Architectural Framework of Existence. In S. A. David, I. Boniwell, \& A. Conley Ayers (Eds.), The Oxford Handbook of Happiness (pp. 942-984). Oxford: Oxford University Press. https://doi.org/10.1093/oxfordhb/9780199557257.013.0070

Sullivan, H. S. (1953a). Conceptions of Modern Psychiatry. New York: Norton.

Sullivan, H. S. (1953b). The Interpersonal Theory of Psychiatry. New York: Norton.

Tinsley, H. E. A., \& Tinsley, D. J. (1987). Uses of Factor Analysis in Counseling Psychology Research. Journal of Counseling Psychology, 34, 414-424.

https://doi.org/10.1037/0022-0167.34.4.414

Triandis, H. C. (1995). Individualism and Collectivism. Boulder, CO: Westview. 
Ullman, J. B. (2013). Structural Equation Modeling (Chapter 14). In B. Tabachnick, \& L. Fidell (Eds.), Using Multivariate Statistics (pp. 681-785). Boston, MA: Pearson Education Inc.

Vulic-Prtoric, A., \& Tkalic, R. G. (2016). Faces of Social Anxiety: Fear of Intimacy and Anxiety in Interpersonal Relationships among Croatian Young Adults. In L. K. Anita, B. Dražen, \& J. Tanja (Eds.), Book of Abstracts. 37th STAR Conference (pp. 256-256). Zagreb: Medicinska naklada.

Wang, J., \& Wang, X. (2012). Structural Equation Modeling. Hoboken, NJ: Wiley, Higher Education Press. https://doi.org/10.1002/9781118356258

Watson, D. (2016). Positive Mood Dysfunction in Psychopathology: A Structural Perspective. In A. M. Wood, \& J. Johnson (Eds.), The Wiley Handbook of Positive Clinical Psychology. Hoboken, NJ: Wiley. https://doi.org/10.1002/9781118468197.ch5

Wiggins, J. S. (1973). Personality and Prediction: Principles of Personality Assessment. Reading, MA: Addison-Wesley.

Zhong, C. B., \& Leonardelli, G. J. (2008). Cold and Lonely: Does Social Exclusion Literally Feel Cold? Psychological Science, 19, 838-842.

https://doi.org/10.1111/j.1467-9280.2008.02165.x 